\title{
Investigating public perceptions of carbon dioxide utilisation (CDU) technology: a mixed methods study $\uparrow$
}

\author{
C. R. Jones, ${ }^{\star a c}$ D. Kaklamanou, ${ }^{\text {b }}$ W. M. Stuttard, ${ }^{\text {a }}$ R. L. Radford ${ }^{a}$ \\ and J. Burley ${ }^{a}$
}

Received 5th May 2015, Accepted 10th June 2015

DOI: $10.1039 / c 5 f d 00063 g$

Carbon dioxide utilisation (CDU) technologies hold promise for helping to limit atmospheric releases of $\mathrm{CO}_{2}$ while generating saleable products. However, while there is growing investment in the research and development required to bring CDU to the market, to date there has been very little systematic research into public perceptions of the technology. The current research reports upon the findings of a series of six qualitative focus groups (and an associated questionnaire) held with members of the UK public in order to discuss the perceived benefits and risks of CDU technology. The findings reveal that public awareness of CDU is currently very low and that there is a desire to learn more about the technology. While our participants did, on average, appear to develop an overall positive attitude towards CDU, this attitude was tentative and was associated with a number of caveats. The implications for the findings in terms of the development of communication and broader strategies of public engagements are outlined.

\section{Introduction}

Anthropogenic emissions of carbon dioxide $\left(\mathrm{CO}_{2}\right)$ are a primary cause of current global warming and climate change. ${ }^{1}$ Carbon dioxide utilisation (CDU) technologies have the potential to help mitigate the release of $\mathrm{CO}_{2}$ to the atmosphere by making use of some of the emissions from carbon intensive processes like fossilfuel power generation. By utilising the $\mathrm{CO}_{2}$ as a carbon source for the manufacture of saleable chemical products (e.g. polymers) and fuels, or through direct use in other industries (e.g. enhanced oil recovery); CDU also holds promise for

${ }^{a}$ Department of Psychology, University of Sheffield, Western Bank, Sheffield, UK. E-mail: c.r.jones@sheffield.ac. uk; Tel: +44 (0)114 2226592

${ }^{b}$ Department of Psychology, Sociology and Politics, Sheffield Hallam University, Collegiate Crescent, Sheffield, $U K$

${ }^{c}$ UK Centre for Carbon Dioxide Utilisation (CDUUK), University of Sheffield, Western Bank, Sheffield, UK $\dagger$ The informational video used within the current research is available at http://www.co2chem.co.uk/research-clusters/public-perception. 
generating economic revenue. This revenue could help to offset some of the costs associated with CDU/CCS (carbon capture and storage) processes and present a viable alternative to fossil-fuel based feedstocks in the manufacture of these products. ${ }^{2,3}$ As such, there is growing interest into the research, development and deployment (RD\&D) of CDU technology - exemplified by this Faraday discussion.

\section{Social acceptability of CDU}

A key consideration in the RD\&D of CDU should be the systematic assessment of the social acceptability of the technology. Social acceptability (i.e. the extent to which a phenomenon, like CDU, is endorsed or rejected by key social actors, e.g. politicians, financiers, the general public, etc.) is now recognised as being necessary for the successful implementation of new technologies. ${ }^{4}$

As key groups of actors are known to affect the social acceptability of emerging technologies at a number of levels (e.g. household, community, national), understanding and responding to the opinions of the general public (i.e. examining public acceptability) should be a priority consideration for CDU proponents. ${ }^{5}$ However, with the exception of a preliminary pilot study conducted by the current authors, to date there has been no systematic research in this field. ${ }^{6}$

\section{Assessing public perceptions of CDU}

Public engagement is a diverse term covering any attempt to contact members of the public in order to inform decision making. ${ }^{5}$ Research shows that more deliberative, participatory forms of engagement - which involve affected publics earlier (i.e. upstream) and in a sustained and transparent way - will tend to yield better outcomes for those behind the engagement activity (e.g. increased public trust and decreased objection to decisions, etc.). ${ }^{7,8}$

While there is an emerging precedent for upstream engagement, there are evident challenges and risks to realising this in any meaningful sense with emerging technologies, like CDU. Not only will a lack of awareness of the technology likely prove to be a barrier to people's willingness to engage, but once engaged there are risks that the opinions registered towards the technology could be misleading if appropriate forms of attitude assessment are not employed. Reference to literature on the formative assessment of public opinion to CCS, for example, indicated the potential for registering pseudo-opinions (or pseudoattitudes) if traditional questionnaire-based survey methods were used., ${ }^{\mathbf{9}, 10}$ Pseudo-opinions are, in essence, uniformed judgements that people provide on issues which they have given little or no thought and are problematic as they tend to be weak, unstable and not very predictive of later thought and behaviour., ${ }^{\mathbf{9 1 1}}$

The prospect of registering pseudo-opinions is increased when using traditional questionnaire-based surveys because they provide limited contextual information on the issues being discussed and are often self-completed, thereby offering little opportunity to clarify misunderstanding. In the context of understanding public perceptions of other emerging technologies (e.g. CCS, hydrogen), the spectre of recording pseudo-opinions has been addressed through the use of non-traditional survey methods (i.e. information choice questionnaires [ICQs]) and qualitative research techniques (e.g. focus groups, interviews)., ${ }^{\mathbf{9 1 0 , 1 2 , 1 3}}$ 
Focus groups (FGs), for instance, provide a good forum for exploring controversial, unfamiliar and/or complex issues, by offering a setting within which information can be presented to and discussed by participants, and where responses and understanding can be probed. ${ }^{\mathbf{1 4}}$ If facilitated carefully, FGs provide a useful context for establishing: (a) 'why' people feel the way they do about issues and; (b) how such issues become socially represented and shared. ${ }^{15}$

\section{Comparative case study: public perceptions of CCS}

The importance of seeking to understand and appropriately assess the opinion of the public towards emerging carbon mitigation technologies is exemplified in work into the public perception of CCS. As a sister technology of CDU, such research provides an appropriate analogue for communicating the value of conducting similar work into CDU. For instance, public opinion research conducted over the last decade or so in a number of countries (e.g. USA, ${ }^{10} \mathrm{UK},{ }^{12}$ Europe, ${ }^{16}$ and Japan $^{17}$ ) has proven invaluable in elucidating the roots of subjective concerns about CCS at a national, regional and local level; leading to guidance on how best to tailor education, communication and development practices to more appropriately address public concerns. ${ }^{18-20}$

Together, these studies have illustrated the multifaceted nature of lay (and expert) opinion of CCS, revealing that public attitudes are not simply a sum of anticipated technical risks but are also influenced by myriad social and economic considerations (e.g. mistrust in the proponents of the technology). ${ }^{\mathbf{1 8 2 1}}$

\section{The current research}

We argue that forging a better understanding of emerging public opinion towards CDU is timely and should be seen as an integral accompaniment to the ongoing $\mathrm{RD} \& \mathrm{D}$ of the technology. In view of the current dearth of research into the public opinion of CDU technology, our team is conducting a series of studies with the dual objectives of (1) learning more about public perceptions of the perceived benefits, risks, utility and relevance of CDU; and (2) identifying appropriate means of communicating with the lay public about the science and technology behind CDU (i.e. the 'What a Waste!' programme).

We feel that appropriate engagement and communication efforts should be predicated on developing a systematic understanding of public attitudes towards the technology. As such, the current research builds upon that reported in a recently published communication article ${ }^{6}$ by detailing the results and implications of six qualitative FGs and an associated survey-based activity designed with these objectives in mind.t

In addition to providing insight into people's opinions of CDU, these FGs also provided a forum to 'market test' a pilot informational video about CDU being developed by the CO2Chem Network (www.co2chem.org).

\footnotetext{
\$ The two FGs mentioned as part of the communication article do also feature within the present article. However, the current article presents new systematic analysis of these FGs alongside 4 new FGs, details of which have not previously been published.
} 
To our knowledge this study is the first to formally investigate and assess public perception of CDU. While a relatively small qualitative study, this research should be considered as part of a preliminary but growing body of research in this novel and important field.

\section{Methods}

\section{Participants}

Six focus groups (FGs), each comprising 6-8 participants (44 participants total: 14 female, 30 male; 15-54 years) were convened. All participants were offered a monetary incentive for participating. $\S$ Further details of the participants comprising each FG can be found in Table 1. FGs 1-4 took place at the University of Sheffield in June or December 2013. Participants were recruited via a university volunteers list. FG4 also included members of the general public recruited from the part-time workplace of one of the authors. FGs 5 and 6 were convened in December 2013 and comprised year 11 pupils from a local high school. Staff at the school selected students based upon their interest and ability in science and/or their presence on outreach schemes previously run by the University of Sheffield. All participants were aged 15-16 years; both groups comprised a mix of genders.

\section{Materials}

Focus group information sheet. Provided details of the research team and sponsor; an outline of what to expect from the research activity; and a very brief introduction to CDU. Participants were told that CDU can make use of the $\mathrm{CO}_{2}$ emitted from carbon intensive processes like fossil fuel power generation. They were informed that the $\mathrm{CO}_{2}$ could be used in things like plastic manufacture, meaning that $\mathrm{CDU}$ could help to limit atmospheric $\mathrm{CO}_{2}$ emissions and provide a use for an otherwise 'waste' greenhouse gas.

Pre-discussion questionnaire. Recorded participants' age, gender and occupation; their awareness of CDU and CCS ("Have you heard of Carbon Capture \& Storage/Carbon Dioxide Utilisation?" Yes/No/Don't Know); their self-reported level of knowledge about CDU and CCS ("How much do you think you know about ...?" Not a lot/A little/A fair amount/A lot); their attitudes to CDU and CCS ("Overall, what is your attitude to...?" 5-point Likert scale: very positive to very negative, plus a 'Don't Know' option) and their attitude certainty for both technologies ("How certain or uncertain are you of your attitude to...?” 5-point Likert scale: very certain to very uncertain, plus a 'Don't know' option).

Pre-discussion presentation. Contextualised the FG discussion by presenting participants with some background information on CDU via PowerPoint. This presentation expanded on the information sheet by verbally introducing the research team and outlining the central aims for the focus group (i.e. to gather public opinions on CDU and to aid the creation of a video for the CO2Chem Network).

\footnotetext{
$\S$ Monetary incentives varied by group. All participants age $18+$ received a personal monetary incentive. Members of FGs 1 and 2 each received $£ 20$ on account of the fact they also took part in a secondary research task following the FG. Members of FGs 3 and 4 each received $£ 5$. The high school students did not receive individual payment but the school received a lump-sum of $£ 80$ as reimbursement for the students' time.
} 


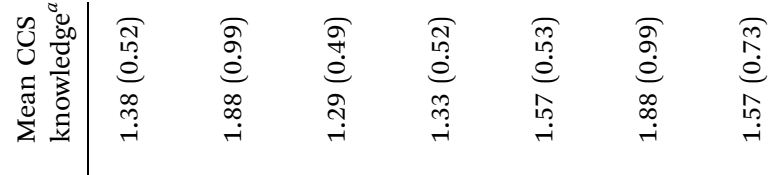

¿

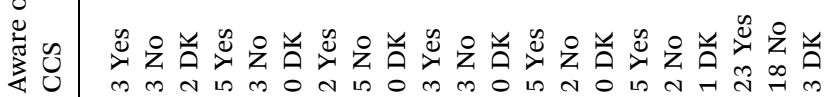

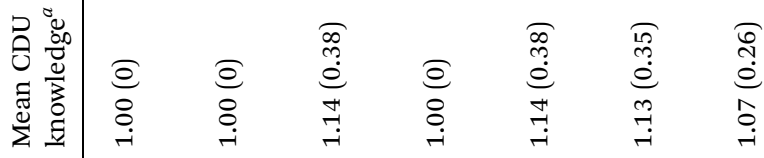

낭

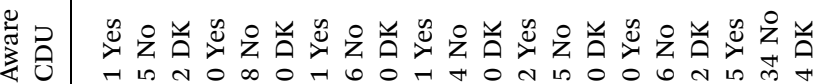

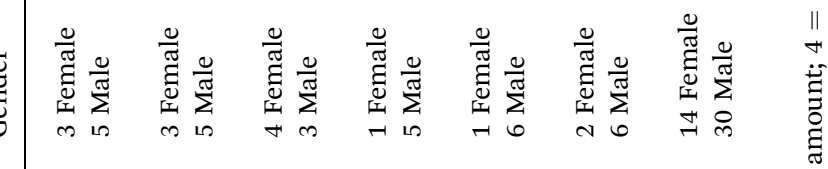

-

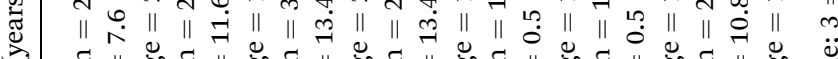

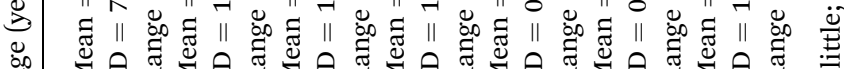

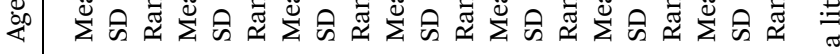

$N$

6

$\infty \quad \exists$

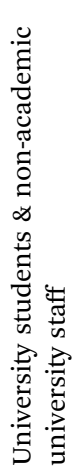

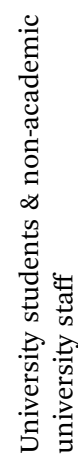

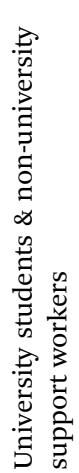

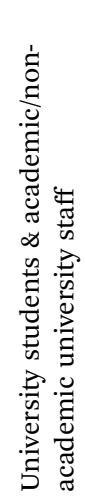

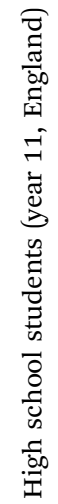

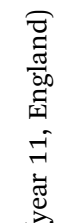

苞

节

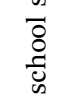

竞

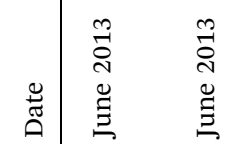

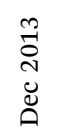

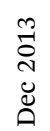

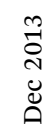

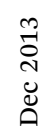

है

今.

N

$n$ 
Participants were briefly talked through a diagram of the CCS process associated with a coal-fired power station. The CCS concept was used as a counterpoint for introducing two often cited benefits of CDU: (a) the value of CDU in offsetting some of the costs associated with CCS by creating saleable chemical products; and (b) the value of CDU in reducing the current reliance on fossil-fuel derived carbon as a feedstock for these products.

Participants were then shown Fig. 1 and informed of some of the products that $\mathrm{CO}_{2}$ could be converted to via CDU. It was noted that many of the depicted conversion processes would require energy and that this would necessarily have to come from renewable sources to mitigate the release of additional $\mathrm{CO}_{2}$ during the manufacture of the products. The presentation ended with a slide outlining a protocol for the remainder of the session. This told participants they would first watch and then comment on a video about CDU before being asked to talk more generally about their opinions of CDU.

Informational video about CDU. A short (75 seconds) informational video combining a mix of cartoon animation and cutaways to real life industrial CDU operations. This video was being developed for the CO2Chem Network in order to communicate fundamental details of CDU technology to an interested, lay audience. $\uparrow$ People watching the video were first introduced to the CO2Chem Network and its purpose in furthering the research and development of CDU. The video then spoke of the relationship between $\mathrm{CO}_{2}$ emissions and climate change. CCS was mentioned as a way of achieving reductions in $\mathrm{CO}_{2}$ emissions and the process of separating and storing the $\mathrm{CO}_{2}$ in geological reservoirs was illustrated. Making use of captured $\mathrm{CO}_{2}$ to create chemical products via $\mathrm{CDU}$ was then introduced and framed as a means of offsetting some of the costs associated with

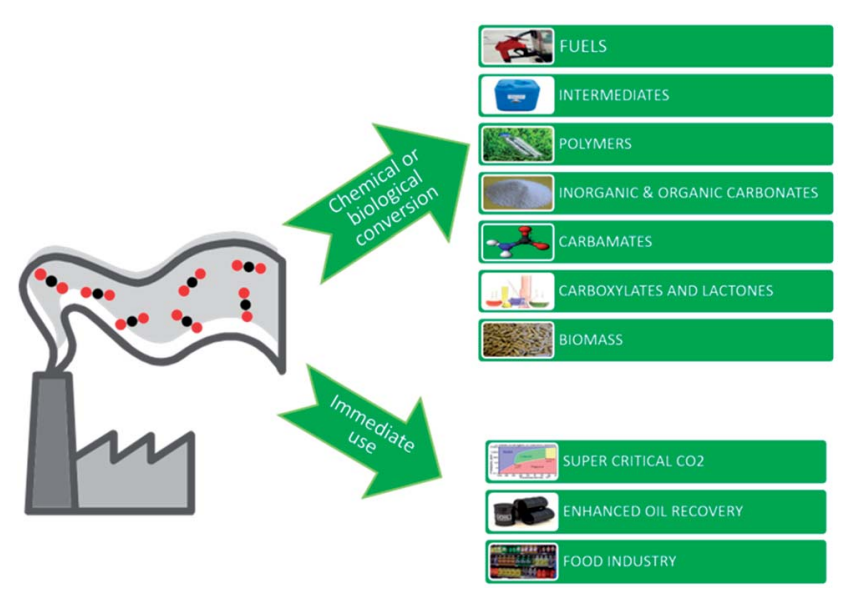

Fig. 1 Some products that $\mathrm{CO}_{2}$ can be converted to via carbon dioxide utilisation (CDU) processes. Source: CO2Chem Network, available at http://www.co2chem.co.uk. Reproduced with the permission of $\mathrm{CO} 2 \mathrm{Chem} \mathrm{Media} \mathrm{and} \mathrm{Publishing} \mathrm{Limited.}$

I There was a problem with the video in FG6, which meant that it did not run smoothly. This issue was taken into consideration when analysing responses towards the video in this group. 
CCS. CDU was also registered as a way to reduce reliance on fossil fuels as a feedstock for producing these chemical products. The video ended by noting that CDU would need energy to produce the chemical products and confirmed that this would necessarily need to come from renewable sources to avoid the release of more $\mathrm{CO}_{2}$ emissions (note: the video is available to view at: www.co2chem.co.uk/research-clusters/public-perception).

Post-discussion questionnaire. Asked for participants' opinion about 26 risks and benefits of CDU technology ("To what extent would you agree or disagree with each of the following statements relating to CDU?" 5-point scale: strongly disagree to strongly agree) (see Appendix 1 for a full list of statements); their self-claimed knowledge, attitude and attitude certainty towards CDU (assessed as outlined in pre-discussion questionnaire); their environmental worldview (revised New Ecological Paradigm [NEP] scale); ${ }^{22}$ and their 'green' identity (4-item scale). ${ }^{23}$

FGs 1 and 2 completed the questionnaire online 1-2 weeks after the FGs. This was necessary as the questionnaire was partially developed on the basis of their responses within the FGs. The remaining FGs (3-6) completed a paper-pencil version of the questionnaire immediately following the focus group discussion.\|

\section{Procedure}

All groups were audio-recorded for later transcription and analysis. Upon arrival participants were provided with refreshments and asked to: (a) read the information sheet; (b) provide their written consent for their participation; and (c) complete the pre-discussion questionnaire.

The FG then began with participants being invited to first provide their names and occupation in order to acquaint themselves with one another. The prediscussion presentation and informational video were then provided and participants were invited to provide feedback on the video - focusing upon both issues of style and content (e.g., how engaging, informative and understandable it was). Discussion about the video lasted approximately 20 minutes, at which point participants re-viewed the video and were invited to provide any final comments. Participants were then asked to discuss their general opinions about CDU and to comment on: (a) any perceived risks and benefits of the technology; (b) the utility of CDU in tackling climate change and; (c) comparative preferences for CDU vs. other carbon mitigation options. This discussion lasted approximately 20 minutes and took a semi-structured format.

Having completed the FG discussion, participants spent the last part of the session completing the post-discussion questionnaire. They were finally invited to ask any final questions or make any final comments before being debriefed, thanked, paid and dismissed.

\section{Data transcription and analysis}

The FG audio-recordings were fully transcribed and analysed using an exploratory thematic analysis approach. ${ }^{25}$ All transcripts were first-coded by one of the authors (WS) who was not present during the FGs. Two additional members of the research

|| Additional questions were included in the post-discussion questionnaire; however, due to small differences in how these questions were asked in FGs 1-2 versus FGs 3-6, these data are not reported on further. 
team (CJ and DK) then independently second-coded one FG transcript using the coding manual created by WS. All coders then convened to discuss and confirm the emergent themes from the FG and to check the reliability of the initial coding scheme created by WS. Any missed coding or disagreement was discussed, before relevant adaptations were made to the coding manual. CJ and DK then independently analysed a further three FGs before convening a second meeting. Within this meeting any disagreements or missed coding were again discussed, before any final, relevant changes were made to the coding manual. WS then used the revised coding manual to recode (where relevant) all the FG transcripts.

\section{Results}

\section{Focus group findings}

The thematic analysis ${ }^{24}$ of the FG data is presented and discussed in accordance with participants' evaluation of: (1) the style and content of the informational video; and (2) the perceived risks and benefits of CDU. In order to aid interpretation of the comments relating to the video, the analysis is structured according to the issues of source, message and audience. ${ }^{25}$

\section{Informational video}

Source factors. Participants noted that it was unclear who the source of the video was. This led to questions about who was behind the video (and CDU more generally) and what their motivation was. The lack of clear authorship, in combination with the perceived "simplistic" nature of the video, negatively affected perceptions of its scientific credibility:

...it definitely wasn't a scientific backed-up video. It could've been an advert for anything. (FG4)

Participants suggested that this issue could be resolved if the video were to include interviews with visible, neutral, expert sources. It was suggested that this would put a face to the technology, which should help to engender more trust in the message content and more generally CDU.

Message factors. Opinions were shaped by the perceived intent of the video (i.e. whether it was designed to entertain or inform) and the groups discussed what level of entertainment might be needed in order to keep peoples interest. Participants agreed that more visually and emotionally engaging video content was needed and they criticised the video for being quite rushed, lacking a consistent visual style and for being quite dull.

Participants questioned whether the information in the video contained sufficient detail and clarity of expression to effectively describe the technology, its purpose and how it differs from CCS.

It [the video] doesn't necessarily very well convey the difference between CCS and CDU. I think you need to make clear that CCS proposes to store it $\left[\mathrm{CO}_{2}\right]$; you are proposing to do something else. On reflection I don't think that comes over particularly well or easily. (FG1)

Some participants suggested that the central message behind the video was not apparent and that the explanation provided in the video needed to follow a more logical, narrative structure in order to appropriately engage with the audience. 
... actually seeing what the problem is and explaining the problem, and what is the solution that you are looking for, that is the main focus of the research, and that was not very deeply touched upon. (FG4)

Comments were also made about some of the technical language (or jargon) used within the video. The following exchange highlights how a number of scientific terms used within the video promoted confusion and misunderstanding among some of our participants, also leading them to question the viability of the video for a general, lay audience.

P1: ...no-one cares about carbonates, I'm probably one of the only people in the university who cares about them, no one knows what they are.

P2: I don't know what synth oil is?

P3: It's synthetic oil.

P2: If [the video] is for a general audience then ...

P4: What does feed-stock mean? When I hear that I think of animals. (Laughter) I don't have a background in chemistry. (FG2)

The video was also perceived to be lacking a balanced critique of CDU. Participants suggested that the potential risks of CDU were not fully addressed and therefore the video came across as one-sided and as an effort to persuade people to like the technology. This imbalance negatively affected the perceived credibility of the message and led to suspicion as to why CDU was being presented in such a positive light.

P1: Like you said, there is no debate [about the risks] so you think well 'what are you not saying'.

P2: It is just like one sided, they are trying to sell you something. (FG3)

Audience factors. Participants commented that it was unclear as to who the intended audience was for the video and agreed that establishing this was a high priority for understanding the purpose of the video and determining the appropriateness of the style and message content.

I don't understand the point of the video, or whether it was trying to tell me to take action or to improve something or to go on the website, I don't know what the point was. (FG1)

Participants tended to agree that the video provided a reasonable basic introduction to CDU but that it was lacking in depth and detail if it were to be used for any other purpose than a basic introduction to the concept. This led to a tension among our participants, who desired more detail (to fully engage in the focus group) but recognised that such detail would increase the length and complexity of the video and thus negatively affect audience interest outside of the experimental context.

Having more facts or figures might make your video altogether a bit boring because it really wouldn't make sense to the wider audience who are not involved in the research. A little bit of it [more detail] would definitely help, giving more examples, actually seeing what the problem is and explaining the problem, and what is the solution that you are looking for, that is the main focus of the research, and that was not very deeply touched upon. (FG4)

Participants' age appeared to shape evaluations of the adequacy of the video. While our adult participants tended to feel that the video was too simplistic and lacked seriousness (bearing in mind the seriousness of the issue it was trying to resolve), our high school groups tended to be less critical on these grounds. It was 
suggested that developing multiple, tailored videos intended for different age groups would be very useful in the future.

I think it [the video style/content] depends on the audience, because you were trying to appeal to everyone by having facts and stuff in as well as the cartoons and the music and stuff, so they should split it up ideally, one for a younger audience and one for older audience. (FG5)

\section{Perceived risks and benefits of CDU}

Three principal areas were discussed by participants, relating to the conceptual issues, technical issues and societal issues associated with CDU. Conceptual issues related to the general underlying principles of the CDU concept and its position relative to other carbon mitigating options (i.e. should we do this); technical issues focused on the technological and market feasibility of CDU (i.e. can we do this); and societal issues related to the implications that might result from an investment in the technology (i.e. what are the consequences).

Conceptual issues. Participants saw CDU to be a technology that would not provide a long term solution to $\mathrm{CO}_{2}$ emissions but would simply stall an inevitable release of $\mathrm{CO}_{2}$ into the atmosphere.

...I like it [CDU] because it is doing something, but it shouldn't be seen as a long term fix, because you are not really going anywhere you are just hiding it $\left[\mathrm{CO}_{2}\right]$ right? (FG2)

Some examples of CDU were particularly susceptible to this criticism (e.g. synthetic fuels) and tended to be negatively evaluated by participants. In contrast, CDU options that implied a longer-term storage of $\mathrm{CO}_{2}$ option (e.g. plastics, concrete) tended to be more positively evaluated.

I think also a lot of what you think about this technology will also depend on its application, [...] if you are getting carbon dioxide from a coal fired power plant and turning that carbon dioxide into polymers that go into plastic, you have created kind of a legitimate carbon sink where it is fixed and it is not going into the atmosphere [...]. But if you are turning it into, somehow managing to turn it into a fossil fuel, that you can use to run on a car, train, whatever, then all the effort that you are going to put into turning that $\mathrm{CO}_{2}$ into some sort of fuel it is still going to end up as carbon dioxide in the atmosphere. (FG1)

While 'delaying the inevitable release of $\mathrm{CO}_{2}$ ' was considered problematic, participants did note the pragmatic value of CDU as a 'stop-gap' technology option (i.e. something which could 'buy us time' as we transition to a low-carbon economy) and as something symbolic of efforts being made to combat climate change.

Ijust feel that it [CDU] is a step in the right direction, providing that [...] if you can do this [capture and use $\mathrm{CO}_{2}$ ] and it works then brilliant. (FG3)

There was also a sense that investing in current CDU technologies could also expedite the development of other CDU options that would not suffer as much from the prospect of re-releasing captured carbon (e.g. using $\mathrm{CO}_{2}$ from the air).

I think if there was potential in the future ofjust not using $\mathrm{CO}_{2}$ from power plants and just using $\mathrm{CO}_{2}$ from the atmosphere then I might feel like the power plant one might be a step on the way and maybe that would swing it [the participant's opinion]. (FG1)

CDU was conceptually criticized for presenting an 'end of pipe' solution to the problem of $\mathrm{CO}_{2}$ emissions; a solution that did not address the root cause of the 
problem (i.e. the activities that were producing $\mathrm{CO}_{2}$ in the first place). In short, CDU was seen as treating the symptoms of the problem as opposed to the cause.

... they [CDU technologies] are trying to fix something but they are not going to the root of the problem, that there is more cars, more population, more pollution, more everything. So they are trying to fix that but not the actual problem that humans are creating more and more pollution. (FG2)

Participants outlined an array of alternative supply and demand side options that they felt would more appropriately address the $\mathrm{CO}_{2}$ problem at source (e.g. promotion of more sustainable living practices, direct investment in renewables). These points are noteworthy bearing in mind some participants believed CDU to be a barrier to necessary lifestyle changes and questioned why renewable energy was being used in the conversion of $\mathrm{CO}_{2}$, rather than being used to more directly power the economy (see below).

Technical issues. High investment costs and cheaper alternatives (e.g. unmitigated emission) were thought to be an economic obstacle to CDU (particularly in a climate of austerity). Participants questioned as to whether CDU would ever become cost-effective without some kind of market intervention.

...there is also a question of cost-effectiveness. Kind of sticking a chimney up and spewing out $\mathrm{CO}_{2}$ I imagine is going to be a whole lot cheaper than the capital investment needed to build either a carbon capture and storage facility or kind of a CDU facility. So there would have to be some sort of pricing mechanism in place. (FG1)

The value of CDU was calculated in more than just economic terms. Many participants suggested that they would endorse the economic cost of investment in CDU if there were significant environmental benefits in doing so. However, there was uncertainty about how readily demonstration CDU operations could be scaled-up and what magnitude of environmental benefit would be realised by CDU.

It [CDU] might be significant but we don't know how significant it might be. General logic says that it should be, because $\mathrm{CO}_{2}$ emissions would increase, we will have more cars, more people, carbon dioxide and utilizing them would help. But I don't know what impact or how much of an impact it could make for the future generations. (FG4)

This uncertainty was related to the fact that participants felt ill-informed about the relative technical and economic feasibility of CDU vs. alternatives. Indeed, while participants appeared to have a generally favourable attitude to CDU, this opinion was evidently conditional upon CDU performing well against these other options.

The question is what alternatives are there, because I'm all for 'we'll spend a little bit more if it has benefits' [CDU]. But if we spend a little bit more on this and there is actually something out there that will work better I'd probably rather spend my money on that. (FG3)

Debate of the likely impact of CDU was also tied to perceptions about the timeframes for bringing the technology to market. There was tension between the seemingly long period of time needed to develop CDU into an economically competitive technology option and the urgency of addressing climate change. However, it was recognised that financial investment in CDU would be necessary for it to become economically competitive. Parallels were drawn with the photovoltaic industry, where investment in solar had eventually made it competitive with more traditional energy sources. 
P1: Well that [economic cost] is an argument that they had against early solar but as oil production starts to come lower and lower, prices do go up and eventually the argument could be that if they develop the technology to do this [CDU] then it will become cost effective...

P2: By the time that happens it will be probably too late.

P1: I don't know; solar got there, solar is cost-efficient now, competitive with oil. (FG2)

Participants were sceptical about whether CDU would result in a net reduction in $\mathrm{CO}_{2}$ emissions across the whole lifecycle. The sense was that emissions associated with the energy needed to convert $\mathrm{CO}_{2}$ into commodity chemicals would undermine any savings resulting from utilisation. Participants drew upon other purportedly 'green' initiatives (e.g. early solar) which turned out to emit more $\mathrm{CO}_{2}$ than they would save to back up this concern.

...we have had too many cons, I think especially some of the early solar panels and things like that when they were so inefficient that [...] once you had it in its box it was saving carbon dioxide, but to produce the sucker and especially ifyou went back to the mines to mine the silicon [...] you were causing so much more damage than anything that you were saving. (FG1)

This issue was deemed particularly important when considering CDU for fuel synthesis. For some participants it seemed counter intuitive (and thermodynamically infeasible) to burn a fossil fuel only to then capture the $\mathrm{CO}_{2}$ produced and expend significant amounts of energy to convert it into another 'fossil fuel'.

Participants' recognition that CDU processes were energy intensive also highlighted the importance to them of using renewables to power the processes. The prospect of using large amounts of renewable energy in CDU, however, led participants to consider whether or not there would be more benefits from just using the renewable energy more directly.

...I like the fact that you show that you use renewable energy to do it. So it is not as if we are going to produce 20 tons of $\mathrm{CO}_{2}$ to get the energy to use up 1 ton of $\mathrm{CO}_{2}$. That to me was a crucial message. (FG1)

...ifyou are using renewable energy to convert carbon dioxide into something else, couldn't you use the renewable energy sources to make energy [electricity]. (FG2)

Societal issues. There was concern that as an 'end of pipe' solution CDU might be used as an excuse for people to continue their environmentally-damaging lifestyles. Participants therefore tended to believe that CDU should only be considered alongside demand-side $\mathrm{CO}_{2}$ reduction strategies.

...people might sort of think like 'great we can, you know, keep going and use loads of cars and doing this that and the other because we've got all this green stuff now'. It's not quite as it might seem. (FG3)

It was also feared that CDU would propagate a 'business as usual' approach to the use of fossil fuels in powering the economy and it was felt that the technology might create societal complacency towards tackling climate change.

...sometimes these things [CDU] can get used to justify more and more coal power stations, 'ah we can capture, you know, a bit of the $\mathrm{CO}_{2}$ from them and make a plastic cup' [...] if it was like that then it wouldn't be worth it. (FG3)

The belief that CDU might produce ostensibly 'unsustainable products' was also of concern to some participants. Plastics and chemicals, even produced from captured $\mathrm{CO}_{2}$, were deemed to run counter to a drive to reduce anthropogenic environmental impact. This led some to devalue the products of CDU. 
...most of the things that are mentioned [in the video] do look like they have a bit of, they don't look exactly environmentally friendly, things like chemicals, you know people don't look at chemicals and think that is good for the environment. Plastic, cars, fuels are not things that people associate with environmentally friendliness. (FG2)

Finally, there was a sense that there might be unknown chemical risks and localised environmental impacts from CDU processes (e.g. acidification of soil or chemical explosions).

There must be dangers involved in like the manipulation of carbon dioxide I would think [...] I'm not sure of the process so... (FG2)

However, in the absence of a full outline of the CDU process, participants felt that they could not comment on these 'capture' risks with certainty. Instead, when considering the risks of $\mathrm{CDU}$, the discussions principally focused on the issue of $\mathrm{CO}_{2}$ sequestration (e.g. $\mathrm{CO}_{2}$ leakage) as opposed to specific concerns with utilisation per se.

Overall evaluation of CDU. Overall, participants appeared to be generally favourable towards CDU. They knew that there were drawbacks but could see value in the idea of trying to recycle $\mathrm{CO}_{2}$. There was also recognition that with new industry would come new jobs, and it was acknowledged that CDU could produce useful products. However, this positivity was caveated by participants' realisation that they still knew very little about CDU, leaving some requiring more convincing of its value.

The idea of recycling $\mathrm{CO}_{2}$ sounds like a good idea in theory but I don't know enough about this process at all, to say whether the process is a good idea. (FG4)

I'm more favourable to capture than to utilisation [...] I believe that the CDU, it is a bit bizarre, it is trying to, well you know it is making plastic that... I'm not convinced by CDU basically. (FG4)

Also, participants only appeared willing to entertain the prospect of investing in CDU alongside investment in other mitigation options.

P1: I think that it [CDU] is good because they are looking at another [option to mitigate climate change], it is just one of the things that they are looking at...

P2: Yes, it is good to consider them all. (FG3)

\section{Quantitative survey findings}

Statistical analysis of some of the key questions in the pre- and post-discussion questionnaires was conducted. This analysis focused on identifying participants' attitudes to CDU and the factors underlying these attitudes. The analysis also indicated the presence of any initial pseudo-opinions.

\section{Pre-discussion questionnaire}

Pseudo-opinions. Of 44 participants, 5 stated that they had heard of CDU before beginning the FG. The remaining 39 participants stated that they had 'not heard' of CDU $(n=34)$ or that they 'didn't know' $(n=5)$. Congruently, selfreported knowledge of CDU was low, with just 2 participants holding 'a little' knowledge of the technology. Factoring out those who had heard of the technology and/or stated holding 'a little' knowledge of CDU $(n=6)$, we investigated the stated pre-discussion attitudes of the participants. While the majority of these participants stated that they held a neutral attitude $(n=9)$ or that they 'didn't know' what their attitude was towards CDU $(n=18)$; 11 participants registered 
holding either a fairly $(n=8)$ or very positive $(n=3)$ attitude. We feel that this can be taken as reasonable evidence of these participants ( $25 \%$ of our sample) having registered pseudo-opinions before beginning the study and, as such, as a justification for using FGs within the current research activities.

\section{Post-discussion questionnaire}

CDU belief statements. Responses to the 26 belief items were assessed by comparing the mean score for each statement with the scale midpoint (i.e. 'neutral') using one-sample $t$-tests. Items where there was a significant deviation from the midpoint were indicative of emerging agreement on the positive or negative attributes of CDU among our participants. Six items showed a significant positive deviation ( $t$ values $\geq 3.85, p$ values $<0.001$ ) from the midpoint, with six showing a significant negative deviation ( $t$ values $\geq 3.60, p$ values $\leq 0.001$ ). Details of these items can be found in Table 2. The remaining items were statistically comparable to the midpoint using a Bonferonni-corrected alpha level of 0.002 ( $t$ values $\leq 3.15, p$ values $\geq 0.003$ ).

The six positive items related to three key issues: (1) the value of CDU as an example of efforts being made to combat climate change; (2) the positive delaying potential for CDU in helping to address climate change; and (3) the potential for

Table 2 CDU belief statements showing significant positive or negative deviation from the scale midpoint ${ }^{a}$

$N \quad$ Mean SD

Positive deviation from scale midpoint

CDU is a step in the right direction for combating climate change

CDU will help to delay the negative effects of having too much $\mathrm{CO}_{2}$

$\begin{array}{lll}41 & 3.78 & 0.85 \\ 41 & 3.59 & 0.97\end{array}$

in the atmosphere

CDU will create new employment opportunities

CDU will produce useful products

$41 \quad 4.05 \quad 0.77$

CDU indicates a commitment to tackling climate change

$\begin{array}{lll}43 & 3.93 & 0.77\end{array}$

CDU will 'buy us time' as we aim to tackle climate change

$\begin{array}{lll}42 & 3.69 & 0.90\end{array}$

$\begin{array}{lll}42 & 3.52 & 0.86\end{array}$

\section{Negative deviation from scale midpoint}

CDU will promote a 'business as usual' approach to current wasteful $\quad 39 \quad 2.56 \quad 0.85$

lifestyle practices

CDU will have a limited impact on $\mathrm{CO}_{2}$ emissions

CDU should only be considered alongside other technologies for

tackling climate change

CDU will draw funding from other technologies better suited to

tackling climate change

CDU will undermine efforts to promote behaviour change among the general public

CDU will only delay the inevitable release of $\mathrm{CO}_{2}$ at high economic cost

$\begin{array}{lll}37 & 2.35 & 0.95\end{array}$

$\begin{array}{lll}41 & 1.81 & 0.90\end{array}$

$33 \quad 2.21 \quad 0.82$

$\begin{array}{lll}40 & 2.43 \quad 1.01\end{array}$

$\begin{array}{lll}38 & 2.42 & 0.91\end{array}$

${ }^{a}$ Notes: negatively worded items were reverse coded such that higher scores for all statements reflected a more pro-CDU opinion. All means discount missing data and respondents who answered 'Don't Know' when responding to the item. Significance vs. scale midpoint (3.00) using one-sample $t$-tests, calculated using Bonferroni-corrected alpha value of $p=0.002$. Statement 1 ("CDU will help to slow the negative effects of climate change") was removed from the analysis due to the misspelling of the word slow in the surveys distributed to FGs 3-6. A full list of the 26 belief statements can be found in Appendix 1. 
CDU to create useful products and employment opportunities. The retained negative items also related to three key issues: (1) the potential for CDU to undermine necessary behaviour and/or lifestyle change; (2) the limited impact of $\mathrm{CDU}$ on $\mathrm{CO}_{2}$ emissions; and (3) a concern that investment in CDU might affect other, more preferred, options for addressing climate change.

Post-discussion knowledge, attitudes and attitude certainty. Forty-three participants completed the post-discussion questions relating to their CDU knowledge, attitude and attitude certainty. Self-claimed knowledge of CDU improved markedly from pre-discussion levels, with 41 participants stating that they now knew either 'a little' $(n=24)$ or 'a fair amount' $(n=17)$ about the technology after the FG. On the basis of these findings, we can be fairly certain that our participants had developed a basic understanding of CDU.

Overall, post-discussion attitudes towards CDU were fairly positive, with the mean attitude (mean $=3.35, \mathrm{SD}=0.84$ ) differing significantly from the scale midpoint, $t(42)=2.72, p=0.010$. Overall, post-discussion attitude certainty (mean $=3.47, \mathrm{SD}=0.80$ ) was also found to differ from the scale midpoint in an affirmative direction, $t(42)=3.83, p<0.001$. This is indicative that participants were on average 'fairly certain' of their opinions about CDU post-discussion.

Post-discussion attitudes, green identity and ecological worldview. With the emerging ambivalence in the perceived 'green credentials' of CDU within our sample (e.g. CDU was seen as a delaying solution for climate change but a threat to lifestyle change), we investigated how participants' green identity and ecological worldview related to their post-discussion attitudes towards CDU. Two of the 44 participants were omitted from these analyses as they did not provide useable response data.

Spearman's rho correlations (two-tailed, pairwise deletion) confirmed the expected significant positive relationship between participants' green identity (mean $=3.92, \mathrm{SD}=0.61)$ and NEP $($ mean $=3.61, \mathrm{SD}=0.48)$ scores, $r(42)=0.31, p$ $<0.045$; and indicated that there was a significant negative relationship between ecological worldview and attitudes (mean $=3.36, \mathrm{SD}=0.85), r(42)=-0.31, p=$ 0.048. Participants with a stronger pro-ecological worldview tended to hold less favourable attitudes towards CDU. The correlation between green identity and attitude was not statistically significant, $r(42)=-0.07, p=0.665$.

\section{Discussion}

This study combined focus group (FG) and survey methods to (a) establish more about public perceptions of CDU; and (b) help identify appropriate means of communicating with the lay public about CDU. While there are limitations to the current research design; we believe we have fulfilled both aims and that our findings offer pioneering insight into the emerging nature of public opinion towards CDU. The remainder of this article will seek to summarize the main findings from the study in relation to public engagement and communication efforts before outlining some of the limitations and key future directions for research in this field.

\section{Main research findings}

The findings indicate that by the end of the research process our participants had, on average, formed a tentative positive attitude towards CDU. This attitude 
appeared to stem principally from the 'delaying potential' offered by CDU in combating climate change, its symbolic status as an attempt to address climate change and its potential to generate useful products and employment opportunities. This positivity was, however, firmly caveated by participants' recognition that they knew little about CDU (related to perceived inadequacies in the informational video) and by several conceptual, technical and societal tensions.

Lack of awareness. Before participating, only 5 of 44 participants stated that they had heard of CDU and even then self-claimed knowledge among those 5 participants was low. Despite claiming to have no awareness or little knowledge of CDU, 11 participants (25\%) claimed to hold (very) positive attitudes towards the technology. While it should not be assumed that these participants were being deceitful, these data confirm the potential for registering 'pseudo-opinions, ${ }^{, 9,11}$ in the current context and thus arguably justify our choice of a focus group method for our research.

The lack of awareness and knowledge of CDU negatively affected participants' ability and willingness to comment on the perceived risks, benefits and applications of the technology. While evidently posing problems for maintaining fluid FG discussion, we feel that this confirms the opportunity facing CDU proponents at the present time. Specifically, not only is there growing evidence of the benefits of upstream public engagement (if done correctly) in helping to foster the success of emerging technology ${ }^{5,8}$ but it is recognised that the optimum time to shape opinion towards new phenomena is when awareness is low and attitudes have yet to form. ${ }^{18} \mathrm{CDU}$ evidently fulfils these criteria and confirms that now is the time to begin a dialogue with the public about CDU.

Importantly, our results also point to the importance of considering the purpose and adequacy of any planned communication in order to lessen the potential for misunderstanding or misrepresentation of the technology. Indeed, one of the key findings from the FGs related to how our participants evaluated the adequacy of the informational video used as an aide to discussion. While many felt that this video could reasonably act to spark public interest in CDU, they questioned the sufficiency of the information in providing the depth of coverage required to debate the technology in full. In short, the perceived quality of the video was tied to beliefs about its intended purpose (and the intended audience). Some participants were also seen to question why they were being asked to discuss CDU at all, which is to say they were unclear as to the purpose of the engagement activity (e.g. what implications there would be for their comments). While we did attempt to clarify the purpose of the research activity, we feel that both these comments underline the same issue: the importance of communicating the purpose of engagement activities and careful selection of communication tools. This conclusion is not novel - the importance of identifying and communicating the goals of planned engagement is well-established $\mathrm{d}^{\mathbf{2 6 , 2 7}}$ - but we feel that the point is illustrated well in the present context, in that a brief informational video was deemed incongruent with the apparent substantive goals of the FG and hence was more negatively evaluated by participants. ${ }^{28}$

There were a number of other stylistic and content concerns that affected participants' evaluations of the adequacy of the video. Issues of message clarity (e.g. words used, structure of narrative) were important and it appeared that trust in the video was undermined by its 'facelessness' and the lack of discussion of risk. These factors led participants to speculate over who would stand to benefit 
from the technology, what risks had gone unmentioned and whether the video had positive persuasive intent. To the extent that trust is used as a heuristic in guiding decision-making has been found to be important in shaping perceptions of similar technologies $\left(\right.$ e.g. $\left.\mathrm{CCS}^{21}\right)$. If the intent of future communications is to provide impartial information so as to allow people to make an informed judgement about CDU technology, then including a fuller description of the anticipated risks and more clearly identifying the source (and beneficiaries) would appear prudent.

Conceptual, technical and social tensions. There was a desire for more information among our participants and it is possible that many of the registered technical concerns (e.g. issues of technical and economic feasibility; lifecycle $\mathrm{CO}_{2}$ emissions and energy critique, etc.), might have been addressed by the presence of more detail on these matters. Arguably, future correspondence should build upon our findings in order to formally address these concerns and counter the emerging gaps and misperceptions in lay understanding of the technology. Importantly though, while more information is perhaps needed, one should not assume that the simple provision of this information alone will guarantee acceptance of CDU. Not only are there known limitations to interventions centred solely on presumed knowledge deficit ${ }^{29}$ but there is evidence within our study that attitudes were shaped by more than a simple lack of technical understanding. Rather, attitudes were also governed by more subjective considerations of the conceptual (e.g. end of pipe critique) and societal (e.g. encouraging wasteful lifestyles) implications of investing in CDU.

Further research into how these conceptual and societal concerns might shape perceptions of CDU is a key avenue for future research. Not only will they likely shape public opinion of CDU in their own right but they may also impact upon how any provided technical information is interpreted and used..$^{30} \mathrm{~A}$ particular focus of future research might be placed upon the apparent conflict forming over the pro-environmental credentials of CDU. For instance, while we found that participants with a stronger environmental worldview tended to be less favourable to CDU; it cannot be inferred that more pro-ecological individuals will automatically reject CDU outright. Rather, whilst they might see CDU as making a direct (e.g. locking away $\mathrm{CO}_{2}$ ) or indirect (e.g. raising the profile of $\mathrm{CO}_{2}$ reduction attempts) contribution to tackling climate change, it is possible that such individuals might show a reluctant acceptance of the technology - akin to that shown in the responses to the recent reframing of nuclear power as a low-carbon energy option. ${ }^{31,32}$

Agnosticism on CDU attributes. While a large number of interesting issues were raised and discussed within the FGs, relatively few were clearly evaluated as positive or negative. Rather, participants remained largely agnostic about many perceived attributes of the technology. These findings are remarkably similar to those from a study by Flynn and colleagues ${ }^{\mathbf{1 3}}$ into public perceptions of hydrogen energy technologies (HET) and help to confirm the challenges faced by engaging in upstream discussions about a new technology. We feel that as more information on the relative costs and benefits of CDU becomes available, systematic investigation of how this information affects public agnosticism on some of the identified issues will be important. Thus it should help to clarify whether the tentative positivity seen towards CDU in our study will likely become strengthened and less caveated, or undermined and more negative over time. 


\section{Limitations \& future directions}

While the current research has succeeded in providing some initial insight into public perceptions of CDU technology; when seeking to transfer our research findings to other groups or contexts, one should carefully consider the limitations relating to this study.

Transferability of findings. The present research was conducted on a convenience sample of participants recruited principally via a university mailing list. While few of the university participants were engineers and/or pure scientists; the self-selected, well-educated nature of our participants presents limitations to the direct transferability of our research findings. This argues in favour of repeating the research - perhaps with more purposive sampling - on participants from more diverse backgrounds. This should help to identify the extent to which the opinions of our participants are socially shared.

Future research could continue to have a qualitative focus although confirming our findings via quantitative methods would also be useful. One option would be to conduct a nationally representative survey of public opinion; however, such activity would need to recognise the issues presented by the low levels of public awareness (e.g. the prospect of registering pseudo-opinions). Distributing an Information-Choice Questionnaire (ICQ) ${ }^{9}$ could present one solution to this problem and formative efforts to pilot a CDU ICQ have already been made by the current authors. ${ }^{6}$

Framing of materials. The perceived imbalance in the description of CDU present within the informational video (i.e. the absence of considerations of risk) indicates that the technology was positively framed in this research. While this did not prevent participants engaging in considering potential drawbacks of CDU, it does have implications for the strength of the conclusions that can be drawn. Specifically, studies show that the manner in which information is presented or framed, can exert an impact upon people's decisions and preferences. ${ }^{33}$ Thus, one could hypothesise that the positive tone of the video may have yielded more favourable opinions of the technology than would have arisen in a context where the potential drawbacks of CDU were more explicitly considered (or were the focus of the video). While the deliberative nature of the FG context (i.e. where both the benefits and risks of CDU were debated) should have lessened the impact of this positive framing in the current context; we contend that a systematic investigation of the impact of purposive framing on comparative preferences for CDU (or different CDU options) presents an important, empirical question for future research.

\section{Conclusions}

With a growing recognition of the impact that public opinion can have in shaping the social acceptance (and likely success) of emerging technologies, ${ }^{4}$ investing time and appropriate resources for developing public engagement and communication strategies is essential. ${ }^{5}$ In the context of CCS, an awareness of the value of public engagement has not only promoted invaluable social scientific research into the factors underlying public perceptions of the technology but has given rise to best practice guidelines designed to inform more effective engagement and education programmes. ${ }^{18,19}$ 
Consistent with this precedent, the current study has provided formative insight into the beliefs that are likely to underlie emerging public opinion of CDU; helping to shed light on the current low level of awareness of the technology and how this might feed technical misunderstanding and shape perceptions about conceptual fit and societal implications. While we found that participants generally valued the idea of recycling $\mathrm{CO}_{2}$, this general-level support masked differences in the favourability of different CDU options and was strongly qualified. We feel that now is the time to work with the findings and limitations of the current study to engage in a fuller programme of research in order to investigate how this qualified support of CDU holds up to further scrutiny and which CDU options are most preferred.

\section{Appendices}

\section{Appendix 1}

The full list of the $26 \mathrm{CDU}$ risk and benefit statements presented to participants in the post-discussion questionnaire ("To what extent would you agree or disagree with each of the following statements relating to CDU?" 5-point scale: strongly disagree to strongly agree). CDU is/will/should/has: (1) a step in the right direction for combating climate change; (2) help to delay the negative effects of having too much $\mathrm{CO}_{2}$ in the atmosphere; (3) create new employment opportunities; (4) be good for the environment; (5) be good for the UK economy; (6) a cost-effective way of tackling climate change; (7) promote a 'business as usual' approach to current wasteful lifestyle practices; (8) have a limited impact on $\mathrm{CO}_{2}$ emissions; (9) only be considered alongside other technologies for tackling climate change; (10) the wrong solution for tackling climate change; (11) produce useful products; (12) be accepted by the general public; (13) indicates a commitment to tackling climate change; (14) be negatively evaluated by the general public; (15) draw funding from other technologies better suited to tackling climate change; (16) undermine efforts to promote behaviour change among the general public; (17) promote an unwelcome continuing use of fossil fuels; (18) only delay the inevitable release of $\mathrm{CO}_{2}$ at high economic cost; (19) alleviate the storage risks associated with Carbon Capture and Storage (CCS); (20) only delay the inevitable release of $\mathrm{CO}_{2}$ at high energy cost; (21) a 'green' technology; (22) many unknown risks; (23) more risks than benefits; (24) 'buy us time' as we aim to tackle climate change; (25) not become a commercial reality in my lifetime; (26) help to slow the negative effects of climate change.

\section{Acknowledgements}

The authors would like to thank Louise Essam for her help in producing the CDU informational video and the CO2Chem network (http://www.co2chem.co.uk) for funding this research (EPSRC grants EP/H035702/1 and EP/K007947/1). The authors would also like to thank Prof. Peter Styring and Katy Armstrong for their assistance in the formative stages of this study.

\section{Notes and references}

1 IPCC, Climate Change 2014: Synthesis Report, Contribution of Working Groups I, II and III to the Fifth Assessment Report of the Intergovernmental Panel on Climate Change, 2014, IPCC, Geneva, Switzerland. 
2 P. Styring, D. Jansen, H. de Coninck, H. Reith and K. Armstrong, Carbon Capture and Utilisation in the Green Economy, UK, 2011, Centre for Low Carbon Futures.

3 Carbon Dioxide Utilisation: Closing the Carbon Cycle, ed. P. Styring, E. A. Quadrelli and K. Armstrong, Elsevier, 2014.

4 R. Wüstenhagen, M. Wolsink, and M. J. Bürer. Energy Policy, 35, 2683.

5 Energy Research Partnership (ERP), Engaging the Public in the Transformation of the Energy System, 2014, available at: http://erpuk.org/wpcontent/uploads/2014/12/ERP-Public-Engagement-Report-May-2014.pdf.

6 C. R. Jones, R. L. Radford, K. Armstrong and P. Styring, J. CO Util., 2014, 7, 51.

7 Renewable Energy and the Public: from NIMBY to Participation, ed. P. DevineWright, Routledge, 2014.

8 J. Wilsdon and R. Willis, See-through science: Why public engagement needs to move upstream, Demos, 2004.

9 M. de Best-Waldhober, D. Daamen and A. Faaij, Int. J. Greenhouse Gas Control, 2009, 3, 322.

10 E. L. Malone, J. J. Dooley and J. A. Bradbury, Int. J. Greenhouse Gas Control, 2010, 4, 419.

11 G. F. Bishop, A. J. Tuchfarber and R. W. Oldendick, Publ. Opin. Q., 1986, 50, 240.

12 S. Shackley, C. McLachlan and C. Gough, Clim. Pol., 2004, 4, 377.

13 R. Flynn, P. Bellaby and M. Ricci, The limits of 'upstream' public engagement: citizens' panels and deliberation over hydrogen energy technologies, in Renewable Energy and the Public: from NIMBY to Participation, ed. P. DevineWright, Routledge, 2014.

14 V. Price and P. Neijens, Int. J. Publ. Opin. Res., 1997, 9, 336.

15 L. Litosseliti, Using Focus Groups in Research, A\&C Black, 2003.

16 P. Upham and T. Roberts, Int. J. Greenhouse Gas Control, 2011, 5, 1359.

17 K. Tokushige, K. Akimoto and T. Tomoda, Int. J. Greenhouse Gas Control, 2007, 101.

18 P. Ashworth, N. Boughen, M. Mayhew and F. Millar, Int. J. Greenhouse Gas Control, 2010, 4, 426.

19 P. Ashworth, J. Bradbury, S. Wade, C. Y. Feenstra, S. Greenberg, G. Hund and T. Mikunda, Int. J. Greenhouse Gas Control, 2012, 9, 402.

20 W. Bruine de Bruin, L. A. Mayer and M. G. Morgan, J. Risk Res., 2015, 1, aheadof-print.

21 B. W. Terwel, E. Ter Mors and D. D. Daamen, Int. J. Greenhouse Gas Control, 2012, 9, 41.

22 R. E. Dunlap, K. D. Van Liere, A. G. Mertig and R. E. Jones, J. Soc. Issues, 2000, 56, 425.

23 L. Whitmarsh and S. O'Neill, J. Environ. Psychol., 2010, 30, 305.

24 V. Braun and V. Clarke, Qual. Res. Psychol., 2006, 3, 77.

25 C. I. Hovland, I. L. Janis and H. H. Kelley, Communication and Persuasion: Psychological Studies of Opinion Change, Yale University Press, 1953.

26 M. C. Powell and M. Colin, Sci. Comm., 2008, 30, 126.

27 R. Wooden, Social Research: An International Quarterly, 2006, vol. 73, p. 1057.

28 A. Stirling, Sci. Tech. Hum. Val., 2008, 33, 262.

29 P. Sturgis and N. Allum, Publ. Understand. Sci., 2004, 13, 55.

30 J. C. Stephens, J. Bielicki and G. M. Rand, Energy Procedia, 2006, 1, 4655. 
31 K. Bickerstaff, I. Lorenzoni, N. F. Pidgeon, W. Poortinga and P. Simmons, Publ. Understand. Sci., 2008, 17, 145.

32 A. Corner, D. Venables, A. Spence, W. Poortinga, C. Demski and N. Pidgeon, Energy Policy, 2011, 39, 4823.

33 D. Chong and J. N. Druckman, Annu. Rev. Polit. Sci., 2007, 10, 103. 